ATLANTA

\title{
Exploration of a Student Project in a Materials Processing Course
}

Prof. Somnath Chattopadhyay, Georgia Southern University 


\title{
EXPLORATION OF A STUDENT PROJECT IN A MATERIALS PROCESSING COURSE
}

\begin{abstract}
As a part of the laboratory module for the junior level course in Materials Processing, a project has been introduced where the students work two hours every week for one semester. They are each expected to fabricate a hacksaw from the provided drawings and stock materials and work under minimal supervision. The project is designed in such a way that the laboratory (shop) work follows closely the lecture classes. The lecture unit on casting is followed by the fabrication of the handle for the hacksaw which is formed out of cast aluminum. The unit on rolling and bending is followed by the bending of the steel bar to produce the frame of the hacksaw; the unit on sheet metal processing is followed by the part of the hacksaw (retainer) that involves cutting and bending sheet metal; the general topic of machining is followed by the production of the tensioner which involves facing and turning on a lathe, and a finishing operation by milling. There are also applications of joining processes like welding and brazing. The students are expected to maintain strict tolerances for every component of the hacksaw and each hacksaw (one per student) is evaluated on the quality of manufacturing surfaces and also on the dimensions as specified in the drawing (within specified tolerance limits). As an added feature, the modules of material and process selection in the program CES EduPack were employed to justify the choice of materials for various components of the hacksaw, and the associated manufacturing processes.
\end{abstract}

\section{INTRODUCTION}

The primary objective of the Materials Processing course was to provide Mechanical Engineering students with basic information on materials and processing needed to transform stock materials into useful value added parts of an assembly. The students are expected to conceptualize the workings of a variety of manufacturing processes as well as the interrelationship of a single process to the other processes involved in the fabrication of a complete assembly. To accomplish this general objective, a laboratory has been introduced in the course where the students work on a project individually. The lab ( 2 hours every week for 15 weeks) follows the lecture classes (three fifty minute sessions every week) very closely. The instruction in the lecture sessions was primarily from text entitled Manufacturing Engineering and Technology by Kalpakjian and Schmidt [1], and was supplemented as necessary from Ashby's text on Materials and Process Selection [2]. The first few chapters of the text by Kalpakjian and Schmidt deals with the concepts of materials science covered in a previous course that is the prerequisite for the current course. Within the manufacturing sequence associated with the laboratory (shop) work, lecture units on casting, forming and shaping, sheet metal working, joining (riveting and spot welding) and machining are effectively integrated in the project that involves the manufacturing and assembly of a hacksaw. The saw blade is the only stock item for the project which the students purchase on their own. The hacksaw drawing is shown in Figure 1 which gives all the necessary dimensions and associated tolerance limits for each components of the assembly, that the students are expected to maintain. 
The handle is made out of cast aluminum - which effectively supplements the lecture unit on casting. The frame is formed by bending which follows the lecture unit on forming and shaping. The retainer is made out of sheet metal, which goes with the unit on sheet metal processing. The frame is riveted to the handle by means of a small aluminum rod that ties the unit on joining. The retainer is spot welded to the frame, an activity that ties with the unit on welding. The tensioner is fabricated from steel stock by a number of machining operations that include facing, turning, milling, drilling, threading, and interference fitting supplementing various units on machining. The assembly is accomplished by means of a number of stock items, which include the saw blade, the screws attaching the blade to the handle end and a wing nut and screw to attach the tensioner.

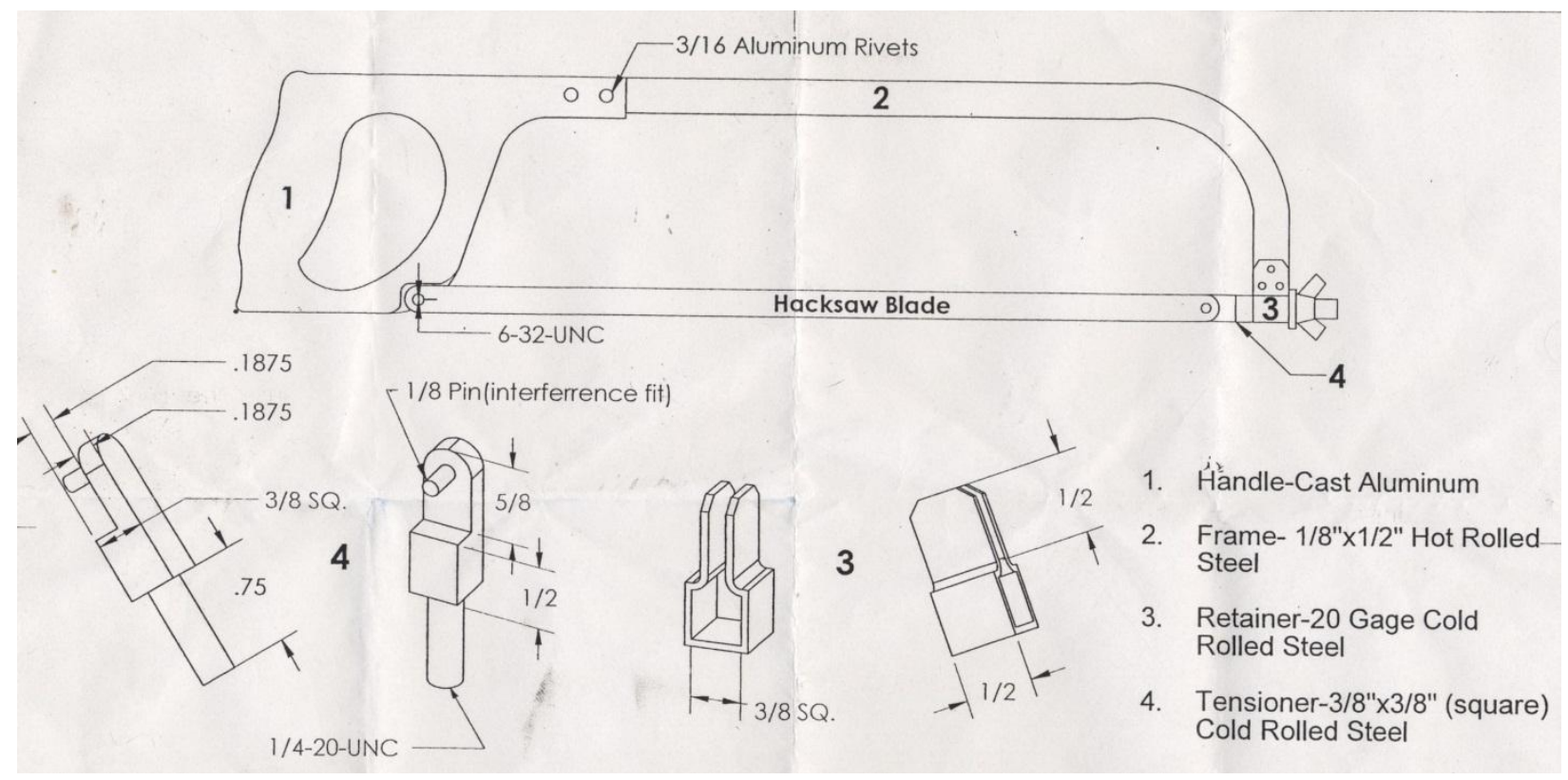

Figure 1 The Hacksaw and the Associated Components

It was anticipated that the lab (shop) activities associated with the fabrication of the hacksaw would improve student knowledge and build confidence in them for effectively applying theory to practice. The laboratory classes demanded significant time commitments by the student and the instructor. A number of demonstrations were provided by the instructor which is highlighted below.

\section{DEMONSTRATIONS}

1. Walk through the manufacturing laboratory; identify equipment and discuss safety.

2. Ramming of sand molds

3. Cutting by a band saw.

4. Bending of steel bar to form the frame, and peen to improve surface fatigue strength.

5. Cutting and forming retainer out of sheet stock.

6. Hand tapping and use of a threading die to thread the tensioner.

7. Spot welding to attach the retainer to the frame

8. Precision layout for the tensioner starting from the stock 
9. Interference fit of a pin in the drilled hole of the tensioner.

10. Work with lathes and mills highlighting the concepts of cutting speed, feed and depth of cut.

11. Preparation of the handle for tapping

12. Drilling and cutting slot in the handle for riveting frame

13. Overall assembly

The manufacturing/assembly processes for various parts of the hacksaw are described next. We start off with the handle, followed by the tensioner, frame, and retainer and close with the overall assembly of the hacksaw.

\section{HANDLE}

The handle was made out of aluminum using sand casting. For this activity the students worked in pairs (two patterns for each mold). The sand was rammed around the patterns (split one for cope and one for drag). The patterns provided to the students had draft (for easy removal of casting) and also incorporated shrinking allowance consistent with the indicated dimensions. It was emphasized that the sand needed to be packed tightly so that the molten metal would not seep through the mold. Gates and runners were carved at the parting plane, and the cope and drag were placed in position. A sprue hole was created at the cope similar to what is shown in Figure 2.

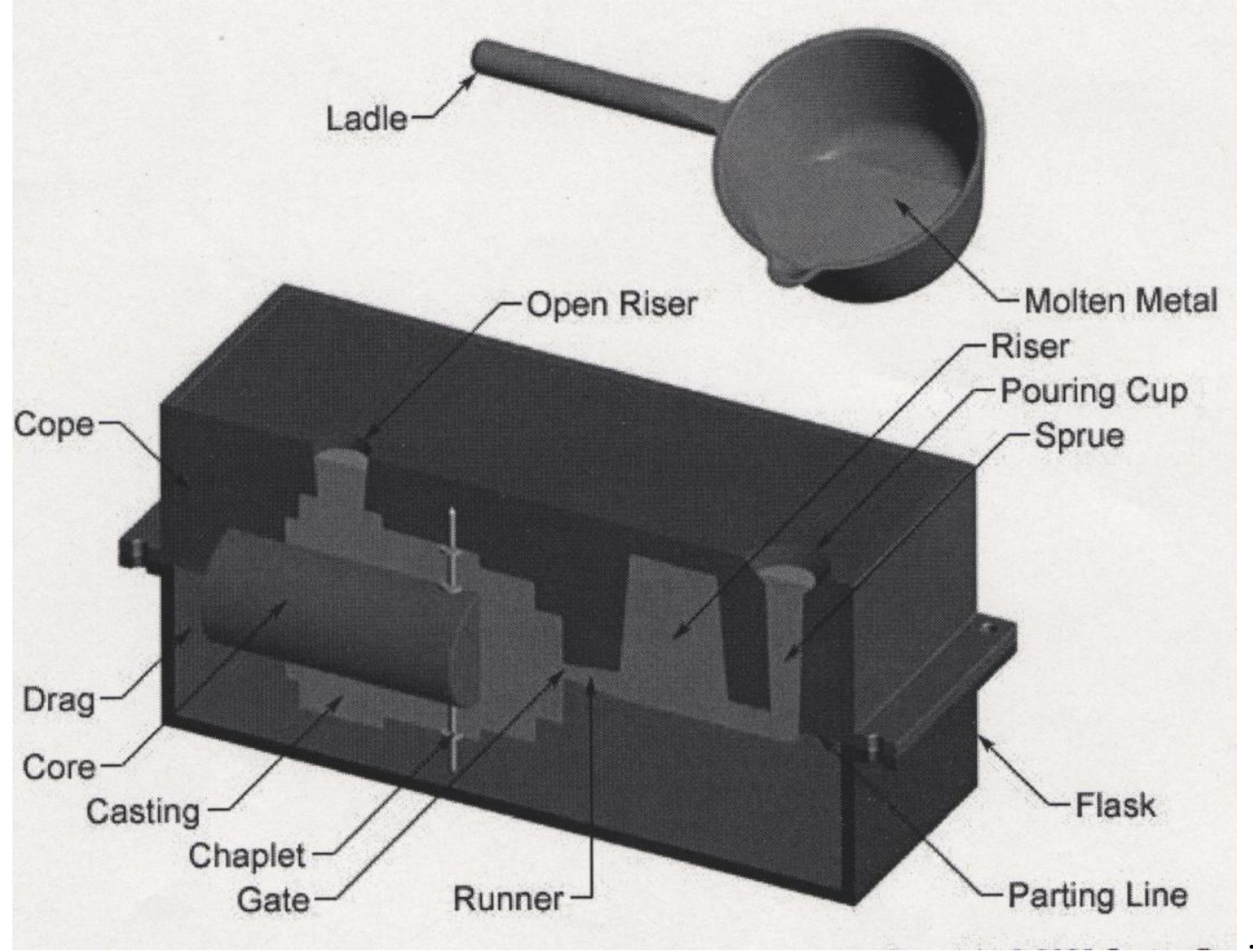

Figure 2 Typical Casting Process 
Molten aluminum $\left(\sim 1300^{\circ} \mathrm{F}\right)$ was poured into the mold. The mold was allowed to cool overnight. The mold was then broken apart and the cast handles were removed. There were two handles in a casting. The handles were separated using a band saw. The extra materials around the handle were retained so that the handle could be held in vise for subsequent filing followed by sanding. The filing and sanding proceeded from a rougher to a finer grit in stages till a highly polished surface was obtained. The saw end of the handle was prepared by cutting a slot and drilled to accommodate the screws; the frame end of the handle was then drilled to accommodate the $3 / 16$ inch aluminum $r$ rivets

\section{Supplemental Activities on Casting the Handle:}

(a) The students were asked to determine the time it took for the molten metal to fill the mold, something they learned in the theory classes using Bernoulli's equation for fluid flow.

(b) Although no risers were used, the students were asked to design risers based on Chvorinov' rule as outlined in the lecture class.

(c) The students were asked to calculate the volumetric shrinkage produced during the casting process

(d) Why was aluminum used as the handle material, and why was the casting used as the manufacturing process?

To answer this question, the students had to justify the material and process selection choice using [2].

\section{TENSIONER}

Cold rolled steel stock ( $3 / 8$ in. $x 3 / 8$ in.) was cut to about $2 \frac{1}{2}$ in using a band saw. Layout operation was used to mark various dimensions. A distance of $5 / 8$ in from one end was milled down to half the stock thickness (0.1875 in.). The curved edge was formed by filing. A pin hole was drilled at this end. The other end that extended 0.75 in was turned down to a diameter of 0.25 in. using several passes on a lathe.

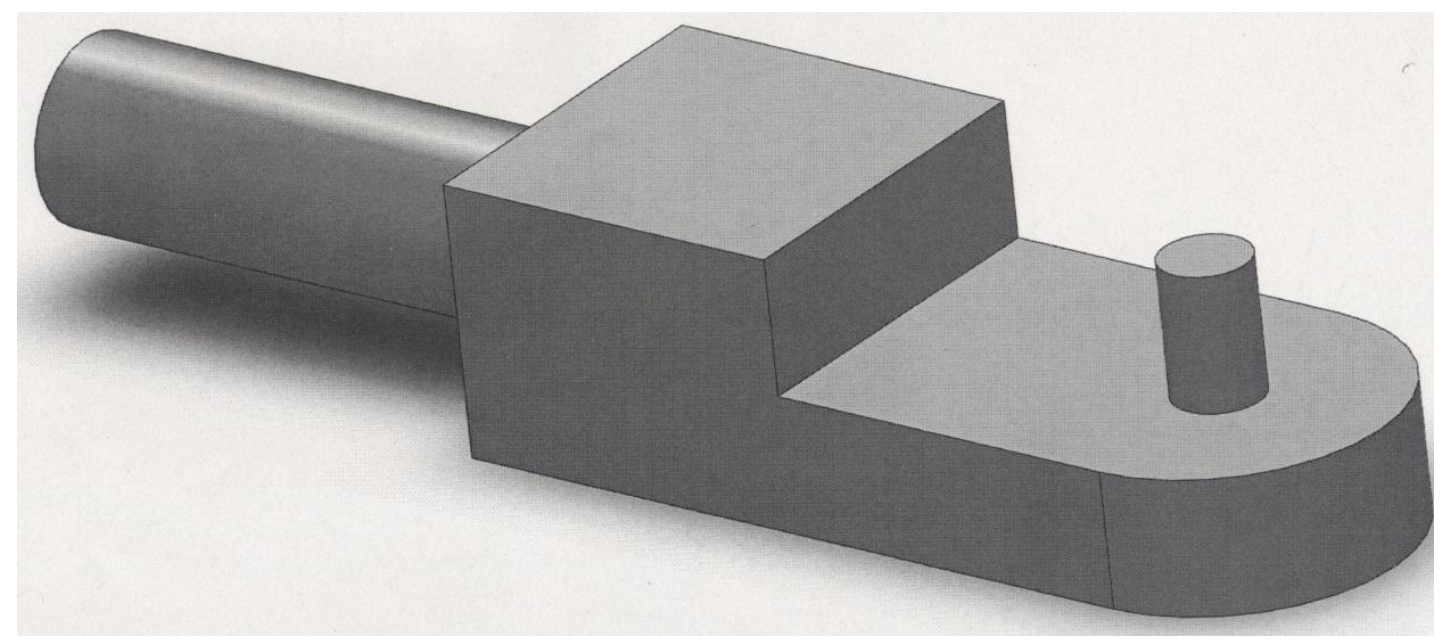

Figure 3 The Tensioner 
This end was next threaded using hand tapping using a threading die to form a $1 / 4-20 \mathrm{UNC}$ thread. The other end of the tensioner in the drilled hole a $3 / 16$ in aluminum rod was interference fitted.

\section{Supplemental Activities on Machining the Tensioner}

(a) The students were required to complete a process sheet containing the stages of rough machining (lathe and mill) and final machining by listing the cutting speeds, the feeds and the depths of cut. They were also required to estimate the MRR (material removal rates) for every stage. Along with the MRR they were also asked to estimate the power required for different stages of machining in a lathe or a mill.

\section{FRAME.}

$1 / 8$ in. $x 1 / 2$ in hot rolled steel stock was cut to a length of about 20 in. Bending tool was clamped into a vise. The stock was placed in the bending device and force was applied gradually to create a bend of about $90^{\circ}$. In the event that the bar was twisted it could be flattened using the vise and/or a hammer. The frame was bent to match the model saw that was provided to the students.

To improve the surface fatigue strength a peening operation was carried out using a ball point hammer all over the frame. The frame was then cut down to size using a band saw by laying out all parts including the saw blade to measure and mark where they would fit together properly.

\section{Supplemental Activities on Frame Bending and Peening}

(a) The dependence of the orientation of the cross-section to the bending stress developed in the frame was discussed. The student were asked to compare the bending strength in the flatwise direction and vertical orientation that produced the most stiffness.

(b) The students were asked to compute the bending force required to produce the $90^{\circ}$ bend, and associated stresses in the frame.

(c) The students were asked to write a mini paper on shot peening to highlight the improvement of the surface fatigue properties.

\section{RETAINER}

A $1 / 2$ in. wide strip of 20 gage cold rolled steel stock was cut to at least 6 in. long. Near the center of the strip $3 / 8$ in wide marks were made for positioning the tensioner on the strip. 


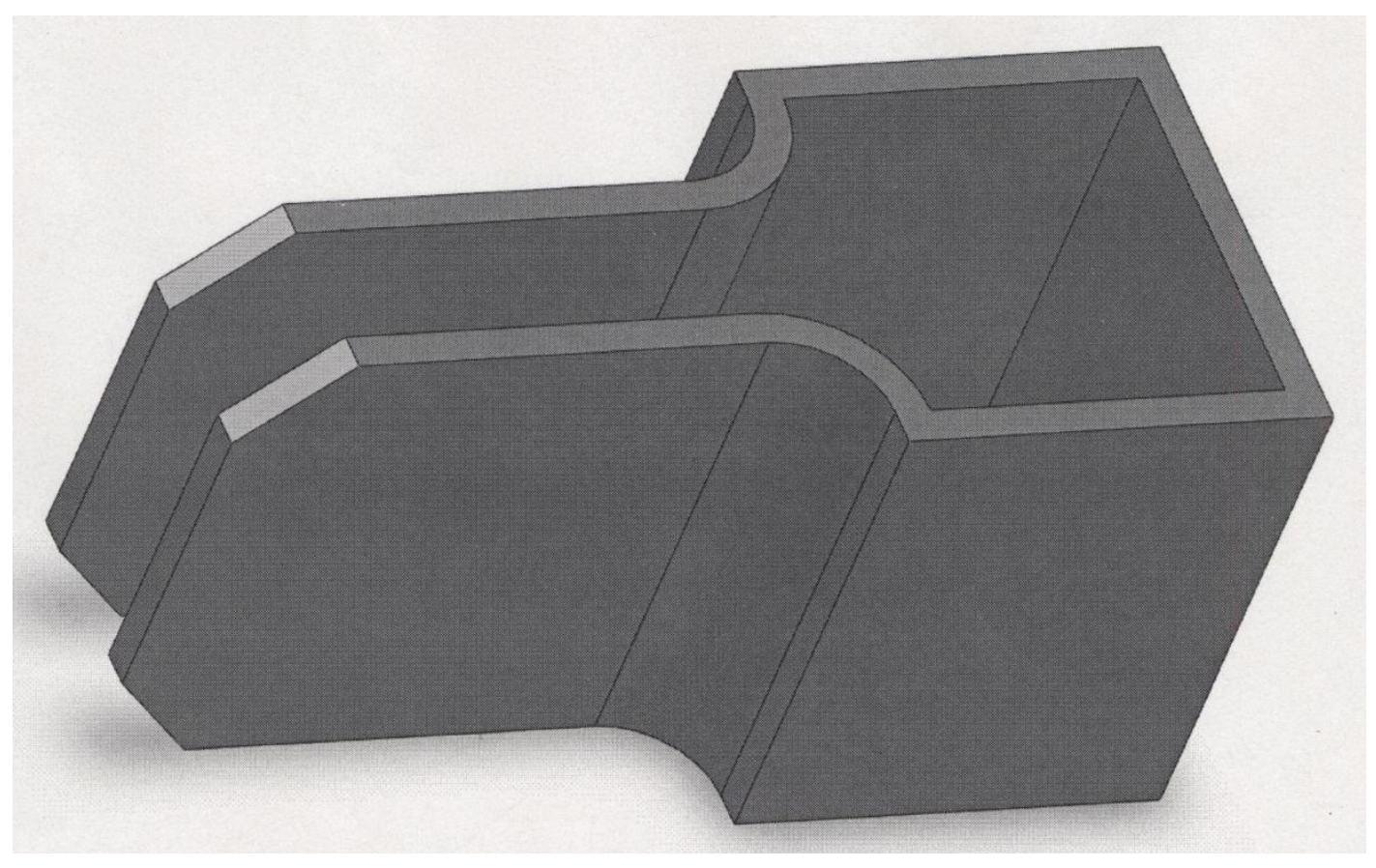

Figure 4 The Retainer

Using sheet metal brake fold at $90^{\circ}$ on the two scribed lines to form a long "U" shape. The bending jig was then used to form the retainer to the indicated shape.

\section{Supplemental Activities on Sheet Metal Processing to produce the Retainer}

(a) The students were asked to determine the force needed to shear the plate to produce the flat piece needed for the retainer.

(b) The students were asked to determine the force needed to bend the cut plate to form the retainer

\section{ASSEMBLY}

The frame was positioned in the handle slot and cut to the correct size. One end of the frame was sanded down and cleaned for spot welding. The spot welder was set to a current of $5 \mathrm{amps}$ and the retainer spot welded to the frame. The other end of the frame was inserted into the handle where rivets were inserted and pounded in place. The saw blade was screwed into the handle. The tensioner was placed in the retainer and the pin is placed at the other end of the blade. A washer and wing nut is screwed at the threaded end of the tensioner and the blade tightened in place.

\section{Supplemental Activities on Assembly of the Hacksaw}

(a) The students were asked to determine the strength of the spot welded connection of the retainer to the frame.

(b) The students were asked to calculate the energy needed to fuse the weld for the spot welding operation with the 5 amp current flow. 


\section{STUDENT HACKSAW EVALUATION}

The handle was evaluated for the overall quality of the casting as evidenced by file marks, the nature of sanding, the amount of remaining flashes and the overall handle shape. The location of the screw hole and its tapping was also considered.

The frame was evaluated for the length of the handle to bend, and that from the bend to the tensioner, the bend angle and the nature of peening on the surface.

The tensioner was evaluated for the overall length (1.75", nominal; 1.745 "- 1,755 " tolerance limits), $3 / 8$ in offset length ( 0.625 " nominal: 0.620 "- 0.630 " tolerance limits), $3 / 8$ in square inside retainer ( 0,5 " nominal; 0.495 "- 0.505 " tolerance limits), $3 / 8$ in offset thickness $(0.1875$ in nominal; 0.1825 "- 0.1925 "tolerance limits), and $1 / 8$ in pin location (.0.1875 in nominal; 0.1825 "0.1925 "tolerance limits). The interference fit of $1 / 8$ in pin was judged whether it was seated, bent or had a rough tip.

The retainer was evaluated for its form and shape, as well as the spot weld attaching the retainer to the frame.

The overall assembly was evaluated for various features such as the rivet opening size, location installation, and whether the handle was broken or cracked at the rivet location. The overall appearance was examined in terms of finish, accuracy with respect to the drawing (Figure 1) and for crookedness and major damage.

\section{CONCLUSION}

The student project effectively integrated the lab activities with the topics presented in the lecture classes. Some students preferred advanced machining (Use of CNC machines) but thought the shop experience was worthwhile. The student evaluations were generally positive and the students enjoyed the lab sessions where they learned a variety of manufacturing and assembly processes, and developed an appreciation for the working of machine tools and other equipment.

The supplemental activities following each manufacturing process helped to tie in the lecture and laboratory classes.

\section{BIBLIOGRAPHY}

[1] Manufacturing Engineering and Technology,, Kalpakjian, S., and Schmidt, S., $6^{\text {th }}$ Edition, Prentice Hall, $2010 .$.

[2] Materials Selection in Mechanical Design, Ashby, M. F., Fourth Edition, Butterworth-Heinneman, 2006 